\title{
COPD exacerbations by disease severity in England
}

\author{
This article was published in the following Dove Press journal: \\ International Journal of COPD \\ I April 2016 \\ Number of times this article has been viewed
}

\section{Evie Merinopoulou' \\ Mireia Raluy-Callado' \\ Sreeram Ramagopalan' \\ Sharon MacLachlan' \\ Javaria Mona Khalid ${ }^{2}$ \\ 'Real-World Evidence, Evidera, ${ }^{2}$ Takeda Development Centre Europe Ltd, London, UK}

Correspondence: Mireia Raluy-Callado Real-World Evidence, Evidera, Metro Building, 6th Floor, I Butterwick, London, W6 8DL, UK

Tel +4420857 65000

Fax +4420857 65I95

Email mireia.raluy@evidera.com
Objectives: Exacerbations of chronic obstructive pulmonary disease (COPD) are associated with accelerated disease progression and are important drivers of health care resource utilization. The study aimed to quantify the rates of COPD exacerbations in England and assess health care resource utilization by severity categories according to the Global Initiative for Chronic Obstructive Lung Disease (GOLD) 2013.

Methods: Data from the Clinical Practice Research Datalink linked to Hospital Episode Statistics were used to identify patients with a COPD diagnosis aged $\geq 40$ years. Those with complete spirometric, modified Medical Research Council Dyspnea Scale information, and exacerbation history 12 months prior to January 1, 2011 (index date) were classified into GOLD severity groups. Study outcomes over follow-up (up to December 31, 2013) were exacerbation rates and resource utilization (general practitioner visits, hospital admissions).

Results: From the 44,201 patients in the study cohort, 83.5\% were classified into severity levels GOLD A: $33.8 \%$, GOLD B: $21.0 \%$, GOLD C: $18.1 \%$, and GOLD D: $27.0 \%$. Mean age at diagnosis was 66 years and $52.0 \%$ were male. Annual exacerbation rates per person-year increased with severity, from 0.83 (95\% confidence interval [CI]: 0.81-0.85) for GOLD A to 2.51 (95\% CI: 2.47-2.55) for GOLD D. General practitioner visit rates per person-year also increased with severity, from 4.82 (95\% CI: 4.74-4.93) for GOLD A to 7.44 (95\% CI: 7.31-7.61) for GOLD D. COPD-related hospitalization rates per person-year increased from less symptoms (GOLD A: 0.28, GOLD C: 0.39 ) to more symptoms (GOLD B: 0.52, GOLD D: 0.84).

Conclusion: Patients in the most severe category (GOLD D) experienced nearly three times the number of exacerbations and COPD-related hospitalizations as those in the least severe category (GOLD A), in addition to increased general practitioner visits. Better patient management to stabilize the disease progression could allow for an improvement in exacerbation frequency and a reduction in health care resource utilization.

Keywords: COPD, exacerbation, resource use, admissions, England, GOLD 2013

\section{Introduction}

Chronic obstructive pulmonary disease (COPD) is a common respiratory condition characterized by progressive airflow obstruction. ${ }^{1}$ Exacerbations of COPD, defined as the acute worsening of symptoms, contribute to the overall severity of the disease and can be an important cause of hospital admission and readmission ${ }^{2}$ leading to significant disability, decreased quality of life, and an increased risk of death. Additionally, the health care resource use associated with the management of COPD in primary and secondary care results in a substantial economic burden borne by national health care systems. ${ }^{3}$

In the UK, COPD is the most common respiratory condition with an estimated prevalence of 33 cases per 1,000 persons in $2013 .{ }^{4}$ We recently showed using UK primary care data that $26.2 \%$ of patients with COPD on December 31,2013 had one 
exacerbation episode in the year prior to diagnosis, and $25.5 \%$ of patients had more than one episode. ${ }^{4}$ Risk factors for frequent exacerbations included disease severity measured by stages of airflow obstruction and levels of dyspnea. A retrospective analysis using the same primary care database found COPD management costs to increase with exacerbation frequency and level of dyspnea., ${ }^{3,5}$ General practitioner (GP) interactions were major cost drivers, followed by hospitalizations unrelated to COPD and exacerbations.

In recent years, the assessment of COPD has evolved from defining disease severity as a function of the degree of airflow limitation to the inclusion of patient symptoms, history of exacerbations, and comorbidities. ${ }^{6}$ The Global Initiative for Chronic Obstructive Lung Disease (GOLD) 2013 strategy $^{7}$ recognizes the importance of a combined assessment of symptom severity and risk of future events determined by exacerbation history, such as recurrent exacerbations, hospital admissions, or mortality for guiding appropriate therapy. According to GOLD 2013, ${ }^{7}$ patients with COPD can be classified into four severity categories: GOLD A (low risk, low symptoms), GOLD B (low risk, more symptoms), GOLD C (high risk, low symptoms), and GOLD D (high risk, more symptoms). More recent updates of the GOLD strategy maintained the same treatment paradigm.

Given the burden of COPD encompasses acute exacerbations requiring hospitalization, it is important to assess the epidemiology and rates of COPD exacerbations and resource use across settings of care. The objectives of this study were to assess the demographic and clinical characteristics of patients with COPD, including prescribed medications; quantify the rates of exacerbations in the COPD population in the UK; and assess the resource utilization in both primary and secondary care according to the latest available at the time - GOLD 2013 severity categories.

\section{Methods}

\section{Data}

The diagnosis and management of COPD in the UK is performed mainly by GPs in the primary care setting; however, the occurrence of acute exacerbations often necessitates hospital treatment. For this reason, data from both the primary and secondary care settings were extracted from the Clinical Practice Research Datalink (CPRD) linked to Hospital Episode Statistics (HES). In 2015, the CPRD covered $\sim 8.5 \%$ of the UK population, including practices in England, Northern Ireland, Scotland, and Wales, with 13.1 million research quality acceptable patient records included in the database, known to be broadly representative of the demographic breakdown of the UK population. ${ }^{8}$ For this study, only the subset of patients in CPRD who could be linked to HES ( $\sim 58 \%$ of the practices) was used. HES contains information on admissions to National Health Service hospitals in England, including records from all admitted patients in acute hospitals, primary care trusts, and mental health trusts. Study protocol approval was given by the Independent Scientific Advisory Committee of the Medicines and Healthcare products Regulatory Agency Database Research (protocol number 15_006R). The data used in this study were non-identifiable, therefore patients' informed consent was not required as part of the protocol approval process.

\section{Study population}

Patients registered in a CPRD practice that could be linked to HES with a diagnosis of COPD identified through Read codes anytime in their medical record up to January 1, 2011 were extracted (Table S1). The validity of using Read codes to identify patients with COPD in the CPRD has been demonstrated in a recent study. ${ }^{9}$ Patients were included if they were 40 years old and above at the time of diagnosis, if they were active on January 1, 2011, and had a minimum of 12 months of active data prior to cohort entry. Patients were followed-up longitudinally until the earliest of: patient death, transfer out of the GP practice, or end of the study period (December 31, 2013).

At cohort entry, the study population was stratified by severity of COPD based on the classification system in the GOLD 2013 management strategy. ${ }^{7}$ Records of spirometry and dyspnea measurements available in CPRD and exacerbations in the 12 months prior to January 1, 2011 were used. More detail on the parameters required for the severity classification is provided in our previous research. ${ }^{4}$

\section{Study measures}

\section{Baseline characteristics}

Patient demographic and clinical characteristics, including age, sex, smoking history, body mass index, and frequent comorbid conditions reported in previous literature, ${ }^{10}$ were described on January 1, 2011 (index date) using data from the 12 months prior (baseline period) as necessary; chronic comorbid conditions were assessed using all available records. Age at time of first COPD diagnosis code recorded also was described. COPD maintenance medication was investigated through prescriptions recorded in primary care during the 6 months prior to index date. Medications of interest included monotherapies and combination treatments as recommended by $\mathrm{GOLD}^{7}$ : reliever medications 
(short-acting beta agonists, short-acting anticholinergics), medications for maintained symptom relief (long-acting beta agonists, long-acting anticholinergics, inhaled corticosteroids), methylxanthines, and oral corticosteroids (OCS) excluding those prescribed during an exacerbation episode.

\section{Outcomes}

The main outcomes in this study were the rate of COPD exacerbations and use of primary and secondary health care resources from index date until end of December 2013.

\section{Exacerbations}

COPD exacerbations were captured using information from both primary and secondary care records, and episodes identified in both settings occurring within a 21-day time period were considered a single episode. In primary care, exacerbations were identified as:

1. A Read code in the clinical record indicating exacerbations or emergency admission to hospital due to COPD (Table S2); or

2. An OCS and oral antibiotic prescription occurring on the same date with the OCS not being used as maintenance treatment; or

3. An OCS or oral antibiotic prescription that is not part of a maintenance episode occurring on the same date as a specific list of Read codes indicating exacerbations.

In secondary care, an exacerbation was defined as a hospitalization in HES with the International Statistical Classification of Diseases and Related Health Problems; 10th Revision (ICD-10) code J44.1 "Chronic obstructive pulmonary disease with acute exacerbation, unspecified" within the reasons for admission.

\section{Resource use}

Health care resources in primary care included GP visits (at the surgery, home, and telephone consultations). Hospitalizations were captured in HES and defined as COPD-related if they had at least one COPD ICD-10 code within the reasons for admission (Table S3).

\section{Statistical analyses}

All analyses were reported for the overall COPD study cohort and by GOLD 2013 severity category. Patient characteristics, including parameters for GOLD classification, were described using number and percentage of patients for categorical variables, and mean (standard deviation) for continuous variables. COPD maintenance medication use was presented using number and percentage of patients who received at least one prescription of that medication group.

Incidence rates of COPD exacerbations (per person-year) and confidence intervals (CIs) were calculated by dividing the number of episodes during the total follow-up by the number of person-years at risk among the overall COPD cohort over the same period. Annual incidence rates of exacerbations, hospitalizations, and GP visits were calculated using the same method for years 2011-2013. Multiple events per patient were accounted for by fitting frailty Poisson models to estimate the variance-corrected CIs around the incidence rates.

Statistical analysis was performed using SAS software version 9.4 and STATA software version 11.

\section{Results}

\section{Study sample}

Overall, 151,203 patients with a Read code indicative of COPD anytime in their medical record prior to January 1, 2011 were identified. Of these, 72,615 patients (48.\%) had their first COPD record at 40 years or older, were active on January 1, 2011, and had 12 months of data history. The subset of 44,201 (61\%) patients registered in a GP practice linked to HES constituted the study cohort.

The study cohort was further stratified by severity at index date based on the GOLD 2013 classification. Of patients with valid forced expiratory volume in 1 second measurements $(74.5 \%)$, the majority presented with mild-to-moderate airflow limitation $(70.0 \%$ ), while $30.0 \%$ had severe or very severe airflow limitation placing them into the high-risk

Table I GOLD classification parameters at index

\begin{tabular}{ll}
\hline & $\begin{array}{l}\text { Overall COPD cohort } \\
(\mathbf{N}=\mathbf{4 4 , 2 0 I}), \mathbf{n}(\%)\end{array}$ \\
\hline FEV $_{1}$ (at least one test recorded) & $32,908(74.5)$ \\
Mild: $\mathrm{FEV}_{1} \geq 80 \%$ predicted & $5,628(18.7)$ \\
Moderate: $50 \% \leq \mathrm{FEV}_{1}<80 \%$ predicted & $15,427(51.3)$ \\
Severe: $30 \% \leq \mathrm{FEV}_{1}<50 \%$ predicted & $7,387(24.6)$ \\
Very severe: $\mathrm{FEV}_{1}<30 \%$ predicted & $1,634(5.4)$ \\
mMRC Dyspnea Scale & $36,914(83.5)$ \\
(at least one score recorded) & \\
Grade 0 & $6,105(16.5)$ \\
Grade I & $13,077(35.4)$ \\
Grade 2 & $9,596(26.0)$ \\
Grade 3 & $6,418(17.4)$ \\
Grade 4 & $1,718(4.7)$ \\
Number of exacerbations & \\
0 & $19,948(45.1)$ \\
I & $11,371(25.7)$ \\
$2+$ & $12,882(29.2)$ \\
\hline
\end{tabular}

Abbreviations: COPD, chronic obstructive pulmonary disease; $\mathrm{FEV}_{1}$, forced expiratory volume in one second; GOLD, Global Initiative for Chronic Obstructive Lung Disease; mMRC, modified Medical Research Council. 
category (Table 1). The modified Medical Research Council (mMRC) scores for dyspnea assessment were recorded in $83.5 \%$ of patients with COPD. More than half of them had an assessment of Grade 0-1 dyspnea (51.9\%) versus 48.1\% with Grade 2 and higher. At least one exacerbation was recorded for $54.9 \%$ of patients in the 12 months prior to index date; $29.2 \%$ of patients presented with two or more exacerbations.

On the basis of available mMRC scores and history of exacerbations, $83.5 \%$ of the overall COPD cohort were classified into the GOLD 2013 severity categories: GOLD A: 28.3\%, GOLD B: 17.5\%, GOLD C:15.1\%, and GOLD D: $22.6 \%$. Due to incomplete recording of mMRC measurements, $16.5 \%$ of patients remained unclassified.

\section{Baseline characteristics}

For the overall cohort, the mean (standard deviation) age at COPD diagnosis was 66.3 years (10.6), 52.0\% were male, and the mean time from diagnosis to index date (January 1, 2011) was 4.7 years. The most frequently recorded comorbidities were hypertension (35.4\%), diabetes (16.9\%), and osteoporosis (9.4\%). Overall, $27.3 \%$ of patients were current smokers and $53.8 \%$ were former smokers, with a mean body mass index of $27 \mathrm{~kg} / \mathrm{m}^{2}$ (Table 2).

Baseline characteristics of patients with COPD by severity category are shown in Table 2 . The mean (standard deviation) age at index ranged from 69.8 years (9.9) for patients in the GOLD C category to 73.9 years (10.6) in patients classified as GOLD B. The distribution of comorbidities was similar across severity groups with the most frequently reported conditions being hypertension (GOLD A: 34.4\%, GOLD B: 39.3\%, GOLD C: 34.5\%, and GOLD D: 34.7\%), followed by diabetes (GOLD A: 14.4\%, GOLD B: 19.9\%, GOLD C: $14.5 \%$, and GOLD D: 18.9\%) and osteoporosis (GOLD A: 6.9\%, GOLD B: 10.5\%, GOLD C: 7.7\%, and GOLD D: $12.4 \%$ ). The highest proportion of patients with a smoking history was recorded in the GOLD D category, with $86.6 \%$ of patients classified as current or former smokers (current: 28.3\%, former: 58.3\%). The use of reliever monotherapy was highest among patients in GOLD A, with $15.8 \%$ of them on short-acting beta agonists, and the highest proportion on controller monotherapy for maintained relief was among patients in the GOLD C category, with $12.1 \%$ on long-acting beta agonists. The majority of patients in the most severe GOLD D category were on a combination therapy $(74.6 \%)$, with the most frequently prescribed combination being long-acting beta agonists + long-acting anticholinergics + inhaled corticosteroids (29.9\%). A total of $22.8 \%$ of patients in the GOLD A category were not on any maintenance medication in the 6 months prior to index date, whereas the proportion of patients not on any treatment in the GOLD D category was low, at 3.7\%.

Patients who could not be classified into GOLD severity categories had a mean age of 71.4 years at January 1, 2011; $53.4 \%$ were females, with a mean body mass index of 27 and $74.5 \%$ were current or former smokers. A high proportion $(36.8 \%)$ had not been prescribed any medication at the time of COPD severity assessment, but no significant differences in the frequency distribution of comorbidities were observed when compared to GOLD classified patients (data not shown).

\section{Rate of COPD exacerbations}

The rate of COPD exacerbations among the overall COPD cohort was 1.43 exacerbations per person-year (95\% CI: 1.42-1.45) (Table 3). Exacerbations increased by severity of COPD, ranging from 0.83 (95\% CI: $0.81-0.85$ ) exacerbations per person-year in GOLD A category to 2.51 (95\% CI: 2.47-2.55) in GOLD D category. The rate of exacerbations among unclassified patients during the observation period was lower than classified patients (1.0 exacerbation per person-year).

During the study period, the annual rates of exacerbations showed a statistically significant year over year increase from 2011 to 2013 (Figure 1) across all GOLD categories. The annual rates of exacerbations increased from $0.69(95 \%$ CI: 0.67-0.71), 1.01 (95\% CI: 0.98-1.04), 1.65 (95\% CI: 1.61-1.70), and 2.39 (95\% CI: 2.35-2.44) per person-year for categories GOLD A, B, C, and D, respectively, in 2011 to 0.97 (95\% CI: $0.94-1.00), 1.33$ (95\% CI: $1.28-1.38)$, 1.88 (95\% CI: 1.83-1.94), and 2.61 (95\% CI: 2.55-2.67) exacerbations per person-year in 2013.

\section{Resource use}

The 2011 rates of GP visits were found to increase with disease severity ranging from 4.82 (94\% CI: 4.74-4.93) GP visits per person-year in GOLD A to 7.44 (95\% CI: 7.31-7.61) in GOLD D. During the study period, the annual rates of GP visits remained stable among patients in the lower severity categories, whereas a decreasing trend was observed in the higher severity categories. The greatest decrease was observed in patients classified as GOLD D, from $7.44(95 \%$ CI: 7.31-7.61) GP visits per person-year in 2011 to 6.91 (95\% CI: 6.75-7.10) in 2013.

COPD-related admissions for the overall follow-up were higher among patients with more symptoms (GOLD B: 0.52, GOLD D: 0.84) compared to patients with less symptoms (GOLD A: 0.28, GOLD C: 0.39). During the study period, the 
Table 2 Baseline characteristics of the overall COPD cohort and by GOLD category

\begin{tabular}{|c|c|c|c|c|c|}
\hline & $\begin{array}{l}\text { GOLD A } \\
(N=\mid 2,493)\end{array}$ & $\begin{array}{l}\text { GOLD B } \\
(\mathbf{N}=7,752)\end{array}$ & $\begin{array}{l}\text { GOLD C } \\
(\mathrm{N}=6,689)\end{array}$ & $\begin{array}{l}\text { GOLD D } \\
(\mathrm{N}=\mathbf{9 , 9 8 0 )}\end{array}$ & $\begin{array}{l}\text { Overall } \\
\text { COPD cohort } \\
(\mathrm{N}=\mathbf{4 4 , 2 0 1 )} \\
\end{array}$ \\
\hline Age at index (January I, 20II), mean (SD) & $69.9(10.4)$ & $73.9(10.6)$ & $69.8(9.9)$ & $72.6(9.9)$ & $71.5(10.7)$ \\
\hline \multicolumn{6}{|l|}{ Sex, n (\%) } \\
\hline Male & $6,802(54.0)$ & $3,810(49.0)$ & $3,645(54.0)$ & $5,297(53.0)$ & $22,953(52.0)$ \\
\hline Female & $5,691(46.0)$ & $3,942(51.0)$ & $3,044(46.0)$ & $4,683(47.0)$ & $21,248(48.0)$ \\
\hline Age at diagnosis, mean (SD) & $65.3(10.2)$ & $68.6(10.7)$ & $64.8(9.8)$ & $66.6(10.0)$ & $66.3(10.6)$ \\
\hline Time since diagnosis (months), mean (SD) & $49.2(38.9)$ & $58.2(43.9)$ & $54.0(42.3)$ & $67.4(47.4)$ & $56.3(43.2)$ \\
\hline \multicolumn{6}{|l|}{ Comorbidities, n (\%) } \\
\hline Myocardial infarction & $854(6.8)$ & $814(10.5)$ & $47 \mid(7.0)$ & $\mathrm{I}, 020(10.2)$ & $3,797(8.6)$ \\
\hline Diabetes & $\mathrm{I}, 805(14.4)$ & $1,546(19.9)$ & $97 \mid(\mid 4.5)$ & I,883 (18.9) & $7,455(16.9)$ \\
\hline Hypertension & $4,292(34.4)$ & $3,046(39.3)$ & $2,308(34.5)$ & $3,464(34.7)$ & I5,647 (35.4) \\
\hline Osteoporosis & $868(6.9)$ & $813(10.5)$ & $517(7.7)$ & $1,235(12.4)$ & $4,162(9.4)$ \\
\hline Anxiety & $215(1.7)$ & $108(1.4)$ & $126(1.9)$ & $225(2.3)$ & $811(1.8)$ \\
\hline Depression & $294(2.4)$ & $205(2.6)$ & $176(2.6)$ & $326(3.3)$ & I, $197(2.7)$ \\
\hline \multicolumn{6}{|l|}{ Smoking history, n (\%) } \\
\hline Unknown & I,407 (II.3) & $\mathrm{I}, 00 \mathrm{I}(\mathrm{I} 2.9)$ & $46 I(6.9)$ & $727(7.3)$ & $4,3 \mid 3(9.8)$ \\
\hline Current smoker & $3,331(26.7)$ & I,904 (24.6) & $2,079(31.1)$ & $2,824(28.3)$ & $12,073(27.3)$ \\
\hline Never smoked & $1,136(9.1)$ & $617(8.0)$ & $533(8.0)$ & $608(6.1)$ & $4,035(9.1)$ \\
\hline Ex-smoker & $6,619(53.0)$ & $4,230(54.6)$ & $3,616(54.1)$ & $5,82 I(58.3)$ & $23,780(53.8)$ \\
\hline BMI $\left(\mathrm{kg} / \mathrm{m}^{2}\right)$, mean (SD) & $27(5.4)$ & $28.1(6.9)$ & $26.4(5.5)$ & $26.7(6.8)$ & $27(6.2)$ \\
\hline \multicolumn{6}{|l|}{ Maintenance therapy, n (\%) } \\
\hline Monotherapy & $5,093(40.8)$ & $2,684(34.6)$ & $2,390(35.7)$ & $2,158(21.6)$ & $14,538(32.9)$ \\
\hline Combination therapy & $4,531(36.3)$ & $4,209(54.3)$ & $3,675(54.9)$ & $7,444(74.6)$ & $22,217(50.3)$ \\
\hline Patients not on any treatment & $2,845(22.8)$ & $846(10.9)$ & $614(9.2)$ & $372(3.7)$ & $7,358(16.6)$ \\
\hline Total monotherapies, n (\%) & $5,093(40.8)$ & $2,684(34.6)$ & $2,390(35.7)$ & $2,158(21.6)$ & $14,538(32.9)$ \\
\hline SABA & $1,968(15.8)$ & $816(10.5)$ & $780(11.7)$ & $490(4.9)$ & $5,079(11.5)$ \\
\hline SAMA & $228(1.8)$ & $93(1.2)$ & $81(1.2)$ & $61(0.6)$ & $528(1.2)$ \\
\hline LABA & I,423 (II.4) & 869 (II.2) & $808(12.1)$ & $867(8.7)$ & $4,625(10.5)$ \\
\hline LAMA & $\mathrm{I}, 224(9.8)$ & $822(10.6)$ & $64 \mid(9.6)$ & $690(6.9)$ & $3,676(8.3)$ \\
\hline LAMA + SABA & $754(6 \mid .6)$ & $594(72.3)$ & 485 (75.7) & $56 \mid(8 I .3)$ & $2,595(70.6)$ \\
\hline LAMA + SAMA & $48(3.9)$ & $37(4.5)$ & $33(5.1)$ & $5 \mathrm{I}(7.4)$ & I 77 (4.8) \\
\hline Methylxanthines & $10(0.1)$ & $6(0.1)$ & $3(0.0)$ & $4(0.0)$ & $33(0.1)$ \\
\hline ICS & $240(1.9)$ & $78(1.0)$ & $77(1.2)$ & $46(0.5)$ & $597(1.4)$ \\
\hline OCS & $24(0.2)$ & $13(0.2)$ & $10(0.1)$ & $6(0.1)$ & $88(0.2)$ \\
\hline Total combination therapies, n (\%) & $453(36.3)$ & $4,209(54.3)$ & $3,675(54.9)$ & 7,444 (74.6) & $22,217(50.3)$ \\
\hline LABA + ICS (as both FDC and combination) & I,884 (I5.I) & I,I3I (I4.6) & $I, I 4 I(\mid 7 . I)$ & I,32I (I3.2) & $6,486(14.7)$ \\
\hline$L A B A+I C S+S A B A$ & $1,262(67.0)$ & $888(78.5)$ & $876(76.8)$ & I, I39 (86.2) & $4,892(75.4)$ \\
\hline LABA + ICS + SAMA & $24 \mid(\mid 2.8)$ & $288(25.5)$ & $234(20.5)$ & $452(34.2)$ & $1,368(21.1)$ \\
\hline LABA + LAMA + ICS & $\mathrm{I}, 25 \mathrm{I}(10.0)$ & $\mathrm{I}, 45 \mathrm{I}(\mathrm{I} 8.7)$ & $1,300(19.4)$ & $2,989(29.9)$ & $7,537(17.1)$ \\
\hline$L A B A+L A M A+I C S+S A B A$ & $926(74.0)$ & $1,217(83.9)$ & I,I03 (84.8) & $2,719(91.0)$ & $6,426(85.3)$ \\
\hline LABA + LAMA + ICS + SAMA & $46(3.7)$ & $60(4.1)$ & $88(6.8)$ & $231(7.7)$ & $470(6.2)$ \\
\hline LAMA + ICS & $59(0.5)$ & $39(0.5)$ & $35(0.5)$ & $49(0.5)$ & $197(0.4)$ \\
\hline LAMA + ICS + SABA & $34(57.6)$ & $28(7 \mid .8)$ & $29(82.9)$ & $40(81.6)$ & $143(72.6)$ \\
\hline LAMA + ICS + SAMA & $3(5.1)$ & $5(12.8)$ & I (2.9) & $6(12.2)$ & $15(7.6)$ \\
\hline LABA + LAMA & $779(6.2)$ & $967(12.5)$ & $744(11.1)$ & $1,679(16.8)$ & $4,54 \mid(10.3)$ \\
\hline SABA + SAMA only & $368(2.9)$ & $278(3.6)$ & $199(3.0)$ & $208(2.1)$ & I, $195(2.7)$ \\
\hline Methylxanthines + ICS & $47(0.4)$ & $63(0.8)$ & $44(0.7)$ & $143(1.4)$ & $360(0.8)$ \\
\hline Methylxanthines + LABA & $36(0.3)$ & $42(0.5)$ & $34(0.5)$ & $98(1.0)$ & $25 \mathrm{I}(0.6)$ \\
\hline Methylxanthines + LAMA & $7(0.1)$ & $15(0.2)$ & $7(0.1)$ & $24(0.2)$ & $63(0.1)$ \\
\hline Methylxanthines + (LABA or LAMA or ICS) & $97(0.8)$ & $212(2.7)$ & $166(2.5)$ & $916(9.2)$ & $\mathrm{I}, 543(3.5)$ \\
\hline Any other combinations, $\mathrm{n}(\%)$ & $3(0.0)$ & II $(0.1)$ & $5(0.1)$ & $17(0.2)$ & $44(0.1)$ \\
\hline Patients not on any of the above treatments, $\mathrm{n}(\%)$ & $2,845(22.8)$ & $846(10.9)$ & $614(9.2)$ & $372(3.7)$ & $7,358(16.6)$ \\
\hline
\end{tabular}

Abbreviations: BMI, body mass index; COPD, chronic obstructive pulmonary disease; FDC, fixed-dose combination; GOLD, Global Initiative for Chronic Obstructive Lung Disease; ICS, inhaled corticosteroids; LABA, long-acting beta agonists; LAMA, long-acting anticholinergics; n, number of patients; OCS, oral corticosteroids; SABA, shortacting beta agonists; SAMA, short-acting anticholinergics; SD, standard deviation. 
Table 3 Rates of exacerbations during the follow-up period (per person-year) by GOLD category

\begin{tabular}{llllll}
\hline $\begin{array}{l}\text { GOLD } \\
\text { category }\end{array}$ & $\begin{array}{l}\text { Total person- } \\
\text { years at risk }\end{array}$ & $\begin{array}{l}\text { Total number of } \\
\text { exacerbations }\end{array}$ & $\begin{array}{l}\text { Rate of exacerbations } \\
\text { (per person-year) }\end{array}$ & $\begin{array}{l}\mathbf{9 5 \%} \mathbf{C l} \\
\text { lower }\end{array}$ & $\begin{array}{l}\mathbf{9 5 \%} \mathbf{C l} \\
\text { upper }\end{array}$ \\
\hline All patients & $106,382.69$ & 152,403 & 1.43 & 1.42 & 1.45 \\
GOLD A & $31,967.67$ & 26,562 & 0.83 & 0.81 & 0.85 \\
GOLD B & $18,437.71$ & 21,480 & 1.17 & 1.14 & 1.19 \\
GOLD C & $16,638.72$ & 29,666 & 1.78 & 1.74 & 1.82 \\
GOLD D & $23,077.24$ & 57,893 & 2.51 & 2.47 & 2.55 \\
\hline
\end{tabular}

Abbreviations: $\mathrm{Cl}$, confidence interval; GOLD, Global Initiative for Chronic Obstructive Lung Disease.

annual rates of COPD-related hospitalizations increased from 2011 to 2013 irrespective of severity of COPD (Table 4). For patients in GOLD A and B, COPD-related hospitalizations significantly increased within 2 years from 0.22 (95\% CI: $0.20-0.25)$ and 0.48 (95\% CI: $0.46-0.51)$ admissions per person-year in 2011 to 0.34 (95\% CI: $0.31-0.40)$ and 0.57 (95\% CI: 0.54-0.61) in 2013, respectively. The year over year increase (2011-2012 and 2012-2013) was not statistically significant. Similarly, upward trends in COPD-related rates of hospitalizations were observed for categories GOLD C and D, from 0.36 (95\% CI: $0.33-0.40)$ and 0.79 (95\% CI: $0.75-0.84$ ), in 2011 to 0.44 (95\% CI: $0.40-0.48)$ and 0.85 (95\% CI: 0.81-0.89) in 2013; however, the increase within the two study years was not statistically significant.

No clear pattern was observed in annual non-COPD hospitalization rates among GOLD A, B, C, and D severity categories. A slight decrease over time in the annual rates of non-COPD hospitalizations was seen in categories $\mathrm{C}$ and $\mathrm{D}$, from 0.36 and 0.49 per person-year in 2011 to 0.32 and 0.28 in 2013, respectively (Table 4).

\section{Discussion}

To our knowledge, this is the first study to report exacerbation rates captured in both primary and secondary care by disease severity as outlined in the GOLD 2013 management strategy in the UK. ${ }^{7}$ The rates of exacerbations differed between the GOLD categories and showed a large upward trend with increasing level of disease severity from GOLD A ( 0.83 exacerbations per person-year, 95\% CI: $0.81-0.85$ ) to GOLD D (2.51 exacerbations per person-year, 95\% CI: 2.47-2.55) categories. Our study revealed a year over year increase in the annual rate of exacerbations from 2011 to 2013 across all levels of severity. Using a smaller sample of patients with COPD, prior research in UK primary care assessed the frequency of exacerbations according to mild-moderate, severe, and very severe COPD categories using forced expiratory volume in 1 second measurements as outlined in the 2004 National Institute for Health and Clinical Excellence guidance. ${ }^{1,11}$ The mean annual exacerbation frequency increased from 1.1 in patients with mild-moderate COPD to 2.2 in very severe COPD. Previously published research investigating risk factors for acute exacerbations showed that history of exacerbations is most strongly associated with moderate-to-severe exacerbation frequency. ${ }^{12}$ The frequency of exacerbations has been shown ${ }^{13}$ to contribute to disease progression. Long-term data from previous research ${ }^{14}$ investigating the natural history of the disease suggested a rapid decline in health status after the second severe exacerbation

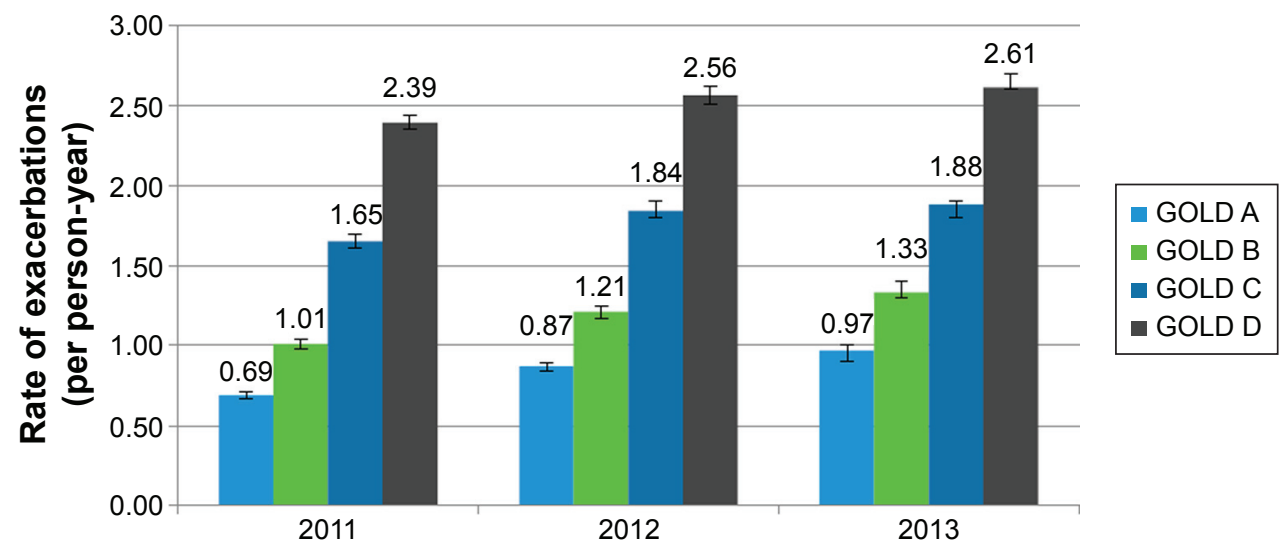

Figure I Annual rates of exacerbations at follow-up (per person-year).

Abbreviation: GOLD, Global Initiative for Chronic Obstructive Lung Disease. 
Table 4 Annual resource use (per person-year) by GOLD category

\begin{tabular}{|c|c|c|c|c|c|}
\hline Year & GOLD & Total person- & COPD-related hospitalizations & Non-COPD hospitalizations & GP visits \\
\hline & category & years at risk & Rate of admissions ( $95 \% \mathrm{Cl}$ ) & $\overline{\text { Rate of admissions }(95 \% \mathrm{Cl})}$ & Rate of visits $(95 \% \mathrm{Cl})$ \\
\hline \multirow[t]{4}{*}{2011} & GOLD A & II,893.16 & $0.22(0.20-0.25)$ & $0.39(0.38-0.40)$ & $4.82(4.74-4.93)$ \\
\hline & GOLD B & $7,195.80$ & $0.48(0.46-0.5 \mathrm{I})$ & $0.45(0.43-0.46)$ & $5.91(5.78-6.07)$ \\
\hline & GOLD C & $6,275.49$ & $0.36(0.33-0.40)$ & $0.36(0.34-0.37)$ & $6.30(6.16-6.47)$ \\
\hline & GOLD D & $9,183.12$ & $0.79(0.75-0.84)$ & $0.49(0.48-0.50)$ & $7.44(7.3 I-7.6 I)$ \\
\hline \multirow[t]{4}{*}{2012} & GOLD A & $10,877.59$ & $0.29(0.25-0.33)$ & $0.44(0.43-0.45)$ & $4.82(4.73-4.93)$ \\
\hline & GOLD B & $6,224.29$ & $0.53(0.50-0.56)$ & $0.43(0.42-0.45)$ & $5.66(5.52-5.83)$ \\
\hline & GOLD C & $5,659.35$ & $0.39(0.36-0.42)$ & $0.38(0.36-0.39)$ & $6.29(6.14-6.48)$ \\
\hline & GOLD D & $7,796.55$ & $0.88(0.83-0.94)$ & $0.40(0.38-0.4 I)$ & $7.16(7.03-7.34)$ \\
\hline \multirow[t]{4}{*}{2013} & GOLD A & $8,957.15$ & $0.35(0.3 \mathrm{I}-0.40)$ & $0.39(0.37-0.40)$ & $4.72(4.62-4.84)$ \\
\hline & GOLD B & $4,888.70$ & $0.57(0.54-0.61)$ & $0.42(0.4 \mathrm{I}-0.44)$ & $5.7 \mid(5.54-5.89)$ \\
\hline & GOLD C & $4,580.30$ & $0.44(0.40-0.48)$ & $0.32(0.30-0.34)$ & $6.09(5.93-6.28)$ \\
\hline & GOLD D & $5,945.35$ & $0.85(0.8 \mathrm{I}-0.89)$ & $0.28(0.27-0.30)$ & $6.91(6.75-7.10)$ \\
\hline
\end{tabular}

Abbreviations: $\mathrm{Cl}$, confidence interval; COPD, chronic obstructive pulmonary disease; GOLD, Global Initiative for Chronic Obstructive Lung Disease; GP, general practitioner.

and high mortality following every severe exacerbation requiring hospitalization.

The National Health Service Quality and Outcomes Framework, ${ }^{15,16}$ an annual reward and incentive program detailing GP practice achievement results, includes indicators for COPD from initial diagnosis to ongoing management. Our findings confirm that patients with COPD are mainly managed by primary care physicians. The annual rates of GP visits were shown to increase with disease severity from $4.8 \mathrm{GP}$ visits per person-year in GOLD A category to $7.4 \mathrm{GP}$ visits per person-year in GOLD D category, in 2011. However, throughout the observation period, GP visits showed a decreasing trend among higher severity categories. Given the progressive nature of the disease, ${ }^{7}$ these results could indicate a shift from the primary to secondary care setting as patients in more severe categories need more specialist support or get hospitalized. The high economic impact of COPD on health care systems has been demonstrated previously ${ }^{17}$ with more than $50 \%$ of COPD direct costs in the UK resulting from inpatient admissions. In our study, the annual rates of COPD-related hospital admissions were highest among patients with higher disease symptoms categorized as GOLD B (2011: 0.5 per person-year) and GOLD D (2011: 0.8 per person-year). In 2013, these rates increased to 0.6 and 0.9 admissions per person-year, respectively. In this descriptive study, no assessment on the risk factors for hospital admission was performed that can explain what the drivers of higher hospital admissions in categories with more symptoms are. A recent study found that history of exacerbation of COPD requiring hospital admission was associated with the highest risk of a new hospitalization for exacerbation, ${ }^{18}$ whereas a previous systematic literature review ${ }^{19}$ found both dyspnea symptoms and previous admissions to be significant factors for readmission. Between GOLD B and C categories, higher rates of COPD-related admissions in the first group indicate that although patients in GOLD B incur fewer exacerbations compared to GOLD C, these are likely to be more severe and lead to hospital admission. On the other hand, patients in GOLD C category have a higher frequency of exacerbations, but these are likely milder episodes that are managed in primary care, in line with our findings that GOLD C patients have higher rates of GP visits compared to GOLD B (2011: 5.91 versus 6.30 visits per person-year). Annual rates for non-COPD hospitalizations did not follow a clear pattern among patients in GOLD A, B, C, and D severity categories, suggesting that COPD symptoms constituted the major differential factor in secondary care resource use across GOLD categories. The prevalence of comorbidities was found to be high among all patients with COPD; however, a similar prevalence distribution across severity categories was observed, with the most common conditions being hypertension, diabetes, and osteoporosis. Our findings were in line with the most common comorbidities associated with COPD reported in previous studies, although precise prevalence numbers differ due to the variation in methodological approaches. ${ }^{10,20}$ Annual rates of non-COPD admissions among newly-diagnosed patients with COPD captured from primary care records were estimated in previous research to be between 0.4 and 0.5 admissions per patient per year for patients with mild to very severe $\mathrm{COPD},{ }^{3}$ corroborating the findings from our study.

The major strengths of our study include the use of a large database representative of the UK population and inclusion of secondary care data from HES. Given the recording of 
exacerbations is not standardized in CPRD, necessitating the use of algorithms to identify these events, ${ }^{3,4,21-23}$ our study improved existing methodology by using a holistic definition combining prescriptions and diagnosis records in primary care with records of hospital admission in the secondary care setting. Records of COPD-related admissions indicating an exacerbation in CPRD were validated by comparing these with data in HES. After investigation of the episodes identified, our conclusion was that exacerbations are generally well reported in primary care with the results being consistent using records from both settings.

A limitation of the study was the missing mMRC records for dyspnea assessment that did not allow the classification of all patients into GOLD categories. Nevertheless, only $17 \%$ of patients remained unclassified. A lower rate of exacerbations among unclassified patients (1.0 exacerbation per personyear), and a high proportion (36.8\%) with any medication prescribed at the time of COPD severity assessment pointed at these patients being less severe; however, this finding might also indicate that their COPD is less monitored and subsequently treated inadequately. An additional study limitation was that patients were not further reclassified by GOLD criteria which may impact results, especially at later time points. Still, based on estimates of disease progression, it is unlikely that many patients will have transitioned between GOLD categories over the course of this study. ${ }^{24,25}$

Length of stay of hospitalizations and data on the severity of exacerbation, such as respiratory failure, high dependency admission, or mortality among hospitalized patients by COPD severity, could not be assessed due to limitations in data availability. Existing evidence from Thomas et $\mathrm{al}^{11}$ in ten GP practices in the UK showed that the median length of hospital stay for COPD-related admissions was similar between severity groups measured by spirometry ( 5 days in mild-moderate [interquartile range: $2-10$ ] and severe COPD [2-9]; 6 days [3-11] in very severe COPD).

The design of our study precluded us from assessing the effect of different COPD maintenance treatments on exacerbation rates, hospital admissions, and exacerbation severity. Of note, existing evidence on comparative treatment efficacy has shown that combination treatments lead to a reduction in exacerbation rates compared to monotherapies or inhaled corticosteroids alone; however, no clear evidence exists using hospital admissions and severity of exacerbation endpoints. ${ }^{26,27}$ Evidence from real-world effectiveness studies is also sparse. Kozma et $\mathrm{al}^{28}$ found no significant differences in hospital admissions among different inhaled therapies with long-acting bronchodilators. Others showed that in comparison to nonusers, maintenance therapy was associated with significantly lower risk of hospitalization and rehospitalization; however, no comparison on the magnitude of the effect between different treatments was performed. ${ }^{29}$ Given limited evidence exists to date, the authors believe this is an interesting area to focus in future research.

\section{Conclusion}

Patients in the most severe category (GOLD D) experienced nearly three times the number of exacerbations and COPDrelated hospital admissions as those in the least severe category (GOLD A). In addition to a year over year increase in exacerbations over the study period, GP visits were found to increase substantially with disease severity; however, for higher severity categories, GP visits decreased over time. These findings suggest a possible shift of patient care from primary to secondary care driven by the progressive severity of the disease. Our findings suggest that management of COPD in earlier stages to stabilize disease progression could be beneficial for reducing exacerbation frequency and health care resource utilization.

\section{Disclosure}

This analysis was sponsored by Takeda Pharmaceuticals International, Inc. Evie Merinopoulou, Mireia Raluy-Callado, Sreeram Ramagopalan, and Sharon MacLachlan are fulltime employees of Evidera and served as paid consultants to Takeda Pharmaceuticals International Inc. for conducting this study. Javaria Mona Khalid is a full-time employee of Takeda Development Centre Europe Ltd. The authors report no other conflicts of interest in this work.

\section{References}

1. National Institute for Health and Care Excellence (NICE). Chronic obstructive pulmonary disease in over 16s: diagnosis and management. NICE clinical guideline 101;2010. Available from: http://www.nice.org. uk/guidance/cg101/resources/chronic-obstructive-pulmonary-diseasein-over-16s-diagnosis-and-management-35109323931589. Accessed February 17, 2016.

2. Wedzicha JA, Donaldson GC. Exacerbations of chronic obstructive pulmonary disease. Respir Care. 2003;48(12):1204-1213; discussion 1213-1215.

3. Punekar YS, Wurst K, Shukla A. Resource use and costs up to two years post diagnosis among newly diagnosed COPD patients in the UK primary care setting: A retrospective cohort study. COPD. Epub 2014 Aug 5.

4. Raluy-Callado M, Lambrelli D, MacLachlan S, Khalid JM. Epidemiology, severity, and treatment of chronic obstructive pulmonary disease in the United Kingdom by GOLD 2013. Int J Chron Obstruct Pulmon Dis. 2015;10(1):925-937.

5. Punekar YS, Shukla A, Mullerova H. COPD management costs according to the frequency of COPD exacerbations in UK primary care. Int $J$ Chron Obstruct Pulmon Dis. 2014;9:65-73.

6. Holmes S, Scullion J. A changing landscape: diagnosis and management of COPD. Br J Nurs. 2015;24(8):432-440. 
7. Global Initiative for Chronic Obstructive Lung Disease (GOLD). Global Strategy for the Diagnosis, Management and Prevention of COPD; 2013. Available from: http://www.goldcopd.org/. Accessed May 21, 2015.

8. Clinical Practice Research Datalink (CPRD). Welcome to the Clinical Practice Research Datalink; 2015. Available from: http:/www.cprd. com/home/. Accessed May 21, 2015.

9. Quint JK, Mullerova H, DiSantostefano RL, et al. Validation of chronic obstructive pulmonary disease recording in the Clinical Practice Research Datalink (CPRD-GOLD). BMJ Open. 2014;4(7):e005540.

10. Chatila WM, Thomashow BM, Minai OA, Criner GJ, Make BJ. Comorbidities in chronic obstructive pulmonary disease. Proc Am Thorac Soc. 2008;5(4):549-555.

11. Thomas M, Radwan A, Stonham C, Marshall S. COPD exacerbation frequency, pharmacotherapy and resource use: an observational study in UK primary care. COPD. 2014;11(3):300-309.

12. Mullerova H, Shukla A, Hawkins A, Quint J. Risk factors for acute exacerbations of COPD in a primary care population: a retrospective observational cohort study. BMJ Open. 2014;4(12):e006171.

13. Donaldson GC, Seemungal TA, Bhowmik A, Wedzicha JA. Relationship between exacerbation frequency and lung function decline in chronic obstructive pulmonary disease. Thorax. 2002;57(10):847-852.

14. Suissa S, Dell'Aniello S, Ernst P. Long-term natural history of chronic obstructive pulmonary disease: severe exacerbations and mortality. Thorax. 2012;67(11):957-963.

15. Health \& Social Care Infomratino Centre (HSCIC). Quality and Outcomes Framework (QOF); 2015. Available from: http://www.hscic. gov.uk/gpes/qof. Accessed July 29, 2014.

16. NHS Employers. Quality and Outcomes Framework guidance for GMS contract 2013/14. 2013.

17. Srivastava K, Thakur D, Sharma S, Punekar YS. Systematic review of humanistic and economic burden of symptomatic chronic obstructive pulmonary disease. Pharmacoeconomics. 2015;33(5):467-488.

18. Mullerova H, Maselli DJ, Locantore N, et al. Hospitalized exacerbations of COPD: risk factors and outcomes in the ECLIPSE cohort. Chest. 2015;147(4):999-1007.
19. Bahadori K, FitzGerald JM. Risk factors of hospitalization and readmission of patients with COPD exacerbation - systematic review. Int J Chron Obstruct Pulmon Dis. 2007;2(3):241-251.

20. Hillas G, Perlikos F, Tsiligianni I, Tzanakis N. Managing comorbidities in COPD. Int J Chron Obstruct Pulmon Dis. 2015;10:95-109.

21. Donaldson GC, Wedzicha JA. COPD exacerbations .1: Epidemiology. Thorax. 2006;61(2):164-168.

22. Donaldson GC, Hurst JR, Smith CJ, Hubbard RB, Wedzicha JA. Increased risk of myocardial infarction and stroke following exacerbation of COPD. Chest. 2010;137(5):1091-1097.

23. Gruffydd-Jones K. GOLD guidelines 2011: what are the implications for primary care? Prim Care Respir J. 2012;21(4):437-441.

24. Vestbo J, Agusti A, Wouters EF, et al. Should we view chronic obstructive pulmonary disease differently after ECLIPSE? A clinical perspective from the study team. Am J Respir Crit Care Med. 2014;189(9): $1022-1030$.

25. Tashkin DP, Celli B, Senn S, et al; UPLIFT Study Investigators. A 4-year trial of tiotropium in chronic obstructive pulmonary disease. N Engl J Med. 2008;359(15):1543-1554.

26. Nannini LJ, Lasserson TJ, Poole P. Combined corticosteroid and longacting beta(2)-agonist in one inhaler versus long-acting beta(2)-agonists for chronic obstructive pulmonary disease. Cochrane Database Syst Rev. 2012;9:CD006829.

27. Kew KM, Dias S, Cates CJ. Long-acting inhaled therapy (beta-agonists, anticholinergics and steroids) for COPD: a network meta-analysis. Cochrane Database Syst Rev. 2014;3:CD010844.

28. Kozma CM, Paris AL, Plauschinat CA, Slaton T, Mackowiak JI. Comparison of resource use by COPD patients on inhaled therapies with long-acting bronchodilators: a database study. BMC Pulm Med. 2011 $11: 61$.

29. Stuart BC, Simoni-Wastila L, Zuckerman IH, et al. Impact of maintenance therapy on hospitalization and expenditures for Medicare beneficiaries with chronic obstructive pulmonary disease. Am J Geriatr Pharmacother. 2010;8(5):441-453. 


\section{Supplementary materials}

Table SI Read codes for COPD

\begin{tabular}{|c|c|}
\hline Read code & Read term \\
\hline $661 \mathrm{M} 300$ & COPD self-management plan agreed \\
\hline $661 \mathrm{~N} 300$ & COPD self-management plan review \\
\hline 66YB.00 & Chronic obstructive pulmonary disease monitoring \\
\hline 66 YB000 & Chronic obstructive pulmonary disease 3 monthly review \\
\hline $66 \mathrm{YBI} 00$ & Chronic obstructive pulmonary disease 6 monthly review \\
\hline $66 \mathrm{Yd} .00$ & COPD accident and emergency attendance since last visit \\
\hline 66YD.00 & Chronic obstructive pulmonary disease monitoring due \\
\hline 66 Ye.00 & Emergency COPD admission since last appointment \\
\hline $66 \mathrm{Yf} .00$ & Number of COPD exacerbations in past year \\
\hline $66 \mathrm{Yg} .00$ & Chronic obstructive pulmonary disease disturbs sleep \\
\hline 66Yh.00 & Chronic obstructive pulmonary disease does not disturb sleep \\
\hline $66 \mathrm{YI} .00$ & COPD self-management plan given \\
\hline 66 Yi.00 & Multiple COPD emergency hospital admissions \\
\hline 66YL.00 & Chronic obstructive pulmonary disease follow-up \\
\hline 66YL.II & COPD follow-up \\
\hline 66YL.12 & COAD follow-up \\
\hline 66YM.00 & Chronic obstructive pulmonary disease annual review \\
\hline 66YS.00 & Chronic obstructive pulmonary disease monitoring by nurse \\
\hline 66YT.00 & Chronic obstructive pulmonary disease monitoring by doctor \\
\hline $8 \mathrm{BMa} 000$ & Chronic obstructive pulmonary disease medication optimisation \\
\hline 8BMW.00 & Issue of chronic obstructive pulmonary disease rescue pack \\
\hline 8CMV.00 & Has chronic obstructive pulmonary disease care plan \\
\hline $8 C M W 500$ & Chronic obstructive pulmonary disease care pathway \\
\hline $8 C R I .00$ & Chronic obstructive pulmonary disease clini management plan \\
\hline $8 \mathrm{H} 2 \mathrm{R} .00$ & Admit COPD emergency \\
\hline $9 e 03.00$ & GP OOH service notified of COPD care plan \\
\hline $9 \mathrm{kf0} .00$ & COPD patient unsuitable for pulmonary rehab - enh serv admin \\
\hline $9 \mathrm{kf0.1I}$ & COPD patient unsuitable for pulmonary rehabilitation \\
\hline $9 \mathrm{NgP} .00$ & On chronic obstructive pulmonary disease supprtv cre pathway \\
\hline 9NgP.II & On COPD (chr obstruc pulmonary disease) supportv cre pathway \\
\hline 9Oi..00 & Chronic obstructive pulmonary disease monitoring admin \\
\hline $90 \mathrm{Oi} 0.00$ & Chronic obstructive pulmonary disease monitoring Ist letter \\
\hline $90 i 1.00$ & Chronic obstructive pulmonary disease monitoring 2 nd letter \\
\hline $90 \mathrm{Oi} 2.00$ & Chronic obstructive pulmonary disease monitoring $3 r d$ letter \\
\hline $90 \mathrm{i} 3.00$ & Chronic obstructive pulmonary disease monitoring verb invite \\
\hline $90 i 4.00$ & Chronic obstructive pulmonary disease monitor phone invite \\
\hline H3...00 & Chronic obstructive pulmonary disease \\
\hline H3...II & Chronic obstructive airways disease \\
\hline H3І..00 & Chronic bronchitis \\
\hline $\mathrm{H} 310.00$ & Simple chronic bronchitis \\
\hline $\mathrm{H} 310000$ & Chronic catarrhal bronchitis \\
\hline $\mathrm{H} 310 \mathrm{z} 00$ & Simple chronic bronchitis NOS \\
\hline $\mathrm{H} 31 \mathrm{I} .00$ & Mucopurulent chronic bronchitis \\
\hline $\mathrm{H} 3 \mathrm{IIOOO}$ & Purulent chronic bronchitis \\
\hline $\mathrm{H} 3 \mathrm{IIIOO}$ & Fetid chronic bronchitis \\
\hline $\mathrm{H} 3 \mathrm{I}$ IzO0 & Mucopurulent chronic bronchitis NOS \\
\hline $\mathrm{H} 312.00$ & Obstructive chronic bronchitis \\
\hline $\mathrm{H} 3 \mathrm{I} 2000$ & Chronic asthmatic bronchitis \\
\hline $\mathrm{H} 3 \mathrm{I} 20 \mathrm{II}$ & Chronic wheezy bronchitis \\
\hline $\mathrm{H} 312100$ & Emphysematous bronchitis \\
\hline $\mathrm{H} 3 \mathrm{I} 2200$ & Acute exacerbation of chronic obstructive airways disease \\
\hline $\mathrm{H} 3 \mathrm{I} 2 \mathrm{z} 00$ & Obstructive chronic bronchitis NOS \\
\hline $\mathrm{H} 313.00$ & Mixed simple and mucopurulent chronic bronchitis \\
\hline
\end{tabular}


Table SI (Continued)

\begin{tabular}{|c|c|}
\hline Read code & Read term \\
\hline H3Іу. 00 & Other chronic bronchitis \\
\hline $\mathrm{H} 3 \mathrm{Iyz00}$ & Other chronic bronchitis NOS \\
\hline $\mathrm{H} 3 \mathrm{Iz} .00$ & Chronic bronchitis NOS \\
\hline $\mathrm{H} 32 . .00$ & Emphysema \\
\hline $\mathrm{H} 320.00$ & Chronic bullous emphysema \\
\hline H320000 & Segmental bullous emphysema \\
\hline H320I00 & Zonal bullous emphysema \\
\hline H320200 & Giant bullous emphysema \\
\hline $\mathrm{H} 320300$ & Bullous emphysema with collapse \\
\hline $\mathrm{H} 320 \mathrm{z} 00$ & Chronic bullous emphysema NOS \\
\hline $\mathrm{H} 321.00$ & Panlobular emphysema \\
\hline $\mathrm{H} 322.00$ & Centrilobular emphysema \\
\hline $\mathrm{H} 32 \mathrm{y} .00$ & Other emphysema \\
\hline $\mathrm{H} 32 \mathrm{y} 200$ & MacLeod's unilateral emphysema \\
\hline $\mathrm{H} 32 \mathrm{yz} 00$ & Other emphysema NOS \\
\hline $\mathrm{H} 32 \mathrm{z} .00$ & Emphysema NOS \\
\hline $\mathrm{H} 36 . .00$ & Mild chronic obstructive pulmonary disease \\
\hline $\mathrm{H} 37 . .00$ & Moderate chronic obstructive pulmonary disease \\
\hline $\mathrm{H} 38 . .00$ & Severe chronic obstructive pulmonary disease \\
\hline $\mathrm{H} 39 . .00$ & Very severe chronic obstructive pulmonary disease \\
\hline H3A...00 & End stage chronic obstructive airways disease \\
\hline $\mathrm{H} 3 y . .00$ & Other specified chronic obstructive airways disease \\
\hline Hзy...II & Other specified chronic obstructive pulmonary disease \\
\hline $\mathrm{H} 3 \mathrm{z} . .00$ & Chronic obstructive airways disease NOS \\
\hline H3z..II & Chronic obstructive pulmonary disease NOS \\
\hline $\mathrm{H} 58 \mathrm{I} .00$ & Interstitial emphysema \\
\hline H582.00 & Compensatory emphysema \\
\hline Hyu3000 & {$[\mathrm{X}]$ Other emphysema } \\
\hline Q312111 & Perinatal mediastinal emphysema \\
\hline SK07.00 & Subcutaneous emphysema \\
\hline
\end{tabular}

Notes: "[X]" indicates cross referenced to specific ICD-I0 codes. Data from the CPRD database (terms and wording are unedited, to match the original source).

Abbreviations: admin, administration; chr obstruct, chronic obstructive; clini, clinical; COAD, chronic obstructive airways disease; COPD, chronic obstructive pulmonary disease; CPRD, Clinical Practice Research Datalink; enh serv admin, enhanced services administration; GP, general practitioner; ICD- I0, International Statistical Classification of Diseases and Related Health Problems; I0th Revision; NOS, not otherwise specified; $\mathrm{OOH}$, out of office hours; rehab, rehabilitation; verb, verbal.

Table S2 Read codes for exacerbations

\begin{tabular}{lll}
\hline Medical code & Read code & Read term \\
\hline 1446 & $\mathrm{H} 3 \mathrm{I} 2200$ & Acute exacerbation of chronic obstructive airways disease \\
7884 & $\mathrm{H} 3 \mathrm{yl} .00$ & Chron obstruct pulmonary dis wth acute exacerbation, unspec \\
100123 & $8 \mathrm{BP} 8.00$ & Antibiotic therapy for acute pulmonary exacerbation \\
11019 & $8 \mathrm{H} 2 \mathrm{R} .00$ & Admit COPD emergency \\
19003 & $66 \mathrm{Ye} .00$ & Emergency COPD admission since last appointment \\
19106 & $66 \mathrm{Yd} .00$ & COPD accident and emergency attendance since last visit \\
46036 & $66 \mathrm{Yi} .00$ & Multiple COPD emergency hospital admissions \\
\hline
\end{tabular}

Notes: Data from the CPRD database (terms and wording are unedited, to match the original source).

Abbreviations: chron, chronic; COPD, chronic obstructive pulmonary disease; CPRD, Clinical Practice Research Datalink; dis, disease; obstruct, obstructive; unspec, unspecified; wth, with. 
Table S3 ICD-10 codes for COPD-related hospitalization

\begin{tabular}{ll}
\hline ICD-10 code & Description \\
\hline J40 & Bronchitis, not specified as acute or chronic \\
Incl: \\
Bronchitis: \\
$\quad$ NOS \\
Catarrhal \\
With tracheitis NOS \\
Tracheobronchitis NOS
\end{tabular}

J4I

J4I.0

J4I.I

J4I.8

J42

$\mathrm{J} 43$

J43.0

j43. 1

$\mathrm{J} 43.2$

J43.8

J43.9

44

J44.0

J44. I

J44.8
Simple and mucopurulent chronic bronchitis

Simple chronic bronchitis

Mucopurulent chronic bronchitis

Mixed simple and mucopurulent chronic bronchitis

Unspecified chronic bronchitis

Incl:

Chronic:

Bronchitis NOS

Tracheitis

Emphysema

MacLeod syndrome

Unilateral:

Emphysema

Transparency of lung

Panlobular emphysema

Panacinar emphysema

Centrilobular emphysema

Other emphysema

Emphysema, unspecified

Emphysema (lung) (pulmonary):

NOS

Bullous

Vesicular

Emphysematous bleb

Other chronic obstructive pulmonary disease

Incl:

Chronic:

Bronchitis:

Asthmatic (obstructive)

Emphysematous

With:

Airways obstruction

Emphysema

Asthma

Bronchitis

Chronic obstructive pulmonary disease with acute lower respiratory infection

Chronic obstructive pulmonary disease with acute exacerbation, unspecified

Other specified chronic obstructive pulmonary

disease

Chronic bronchitis:

Asthmatic (obstructive) NOS

Emphysematous NOS

Obstructive NOS
Tracheobronchitis

Obstructive:

Tracheobronchitis
Table S3 (Continued)

\begin{tabular}{|c|c|}
\hline ICD-IO code & Description \\
\hline \multirow[t]{3}{*}{$\overline{J 44.9}$} & $\begin{array}{l}\text { Chronic obstructive pulmonary disease, } \\
\text { unspecified chronic obstructive: }\end{array}$ \\
\hline & Airway disease NOS \\
\hline & Lung disease NOS \\
\hline \multirow[t]{3}{*}{ J47 } & Bronchiectasis \\
\hline & Incl: \\
\hline & Bronchiolectasis \\
\hline \multirow[t]{3}{*}{ j80 } & Adult respiratory distress syndrome \\
\hline & Incl: \\
\hline & Adult hyaline membrane disease \\
\hline
\end{tabular}

Notes: Data from the World Health Organization (terms and wording are unedited, to match the original source).'

Abbreviations: COPD, chronic obstructive pulmonary disease; ICD-I0, International Statistical Classification of Diseases and Related Health Problems; I0th Revision; incl, including; NOS, not otherwise specified.

\section{Reference}

1. International Statistical Classification of Diseases and Related Health Problems; 10th Revision. World Health Organization. Available from: http://apps.who.int/classifications/icd10/browse/2016/en. Accessed March 10, 2016. 
International Journal of COPD

\section{Publish your work in this journal}

The International Journal of COPD is an international, peer-reviewed journal of therapeutics and pharmacology focusing on concise rapid reporting of clinical studies and reviews in COPD. Special focus is given to the pathophysiological processes underlying the disease, intervention programs, patient focused education, and self management protocols

\section{Dovepress}

This journal is indexed on PubMed Central, MedLine and CAS. The manuscript management system is completely online and includes a very quick and fair peer-review system, which is all easy to use. Visit $\mathrm{http}: / / \mathrm{www}$.dovepress.com/testimonials.php to read real quotes from published authors.

Submit your manuscript here: http://www.dovepress.com/international-journal-of-chronic-obstructive-pulmonary-disease-journal 